Purdue University

Purdue e-Pubs

CTRC Research Publications

Cooling Technologies Research Center

2013

\title{
Local Two-Phase Heat Transfer from Arrays of Confined and Submerged Impinging Jets
}

M. Rau

Purdue University

Suresh V. Garimella

Purdue University, sureshg@purdue.edu

Follow this and additional works at: https://docs.lib.purdue.edu/coolingpubs

Rau, M. and Garimella, Suresh V., "Local Two-Phase Heat Transfer from Arrays of Confined and Submerged Impinging Jets" (2013). CTRC Research Publications. Paper 201.

http://dx.doi.org/http://dx.doi.org/10.1016/j.ijheatmasstransfer.2013.08.041

This document has been made available through Purdue e-Pubs, a service of the Purdue University Libraries. Please contact epubs@purdue.edu for additional information. 


\title{
Local Two-Phase Heat Transfer from Arrays of Confined and Submerged Impinging Jets ${ }^{1}$
}

\author{
Matthew J. Rau, Suresh V. Garimella ${ }^{2}$ \\ School of Mechanical Engineering \\ Purdue University, 585 Purdue Mall, West Lafayette, IN 47907 USA
}

\begin{abstract}
Local heat transfer distributions at high spatial resolution are obtained under two-phase transport conditions in confined and submerged impingement from arrays of miniature jets. The dielectric liquid HFE-7100 is investigated to enable direct cooling of electronic components. Three round orifice geometries with the same total orifice open area are investigated, including a single orifice of $3.75 \mathrm{~mm}$ diameter, a $3 \times 3$ array of $1.25 \mathrm{~mm}$ diameter orifices, and a $5 \times 5$ array of $0.75 \mathrm{~mm}$ diameter orifices. A thin-foil heat source backed by a magnesium-fluoride window is fabricated to allow detailed mapping of the heated surface temperature via infrared (IR) thermography. The rigorous experimental calibration procedures employed, and correction for heat spreading within the thermally conductive IR-transparent window, yield low-uncertainty local heat transfer coefficient distributions. Each of the three orifice geometries is characterized at volumetric flow rates of $450 \mathrm{ml} / \mathrm{min}, 900 \mathrm{ml} / \mathrm{min}$, and $1800 \mathrm{ml} / \mathrm{min}$, resulting in a Reynolds number range of 1920 to 39400. Pressure drop across the confined jets is measured for all experimental cases. The test facility and measurement techniques employed are validated against heat transfer and pressure drop correlations in the literature for single-phase jet impingement from a single round orifice. Spatially resolved temperature contour maps, along with local heat transfer coefficient and boiling curves, are presented as a function of applied heat flux. Boiling is shown to coexist with single-phase convection under the impinging liquid jets. Two-phase enhancement is exhibited at large radial distances from the single jet axis, and in regions between neighboring jets within the arrays. The arrays of jets result in higher area-averaged heat transfer than a single jet at a fixed flow rate; however, the arrays display larger relative nonuniformity in local two-phase heat transfer coefficient and surface temperature. While the $5 \times 5$ array resulted in a higher (and the $3 \times 3$ a lower) pressure drop than the single jet, all orifices displayed pressure drop that is independent of the applied heat flux and vapor generation.
\end{abstract}

\footnotetext{
${ }^{1}$ Submitted for publication in International Journal of Heat and Mass Transfer, March 2013, and in revised form August 2013

${ }^{2}$ Corresponding author. Tel.: +1 765494 5621. E-mail address: sureshg@purdue.edu.
} 


\section{Nomenclature}

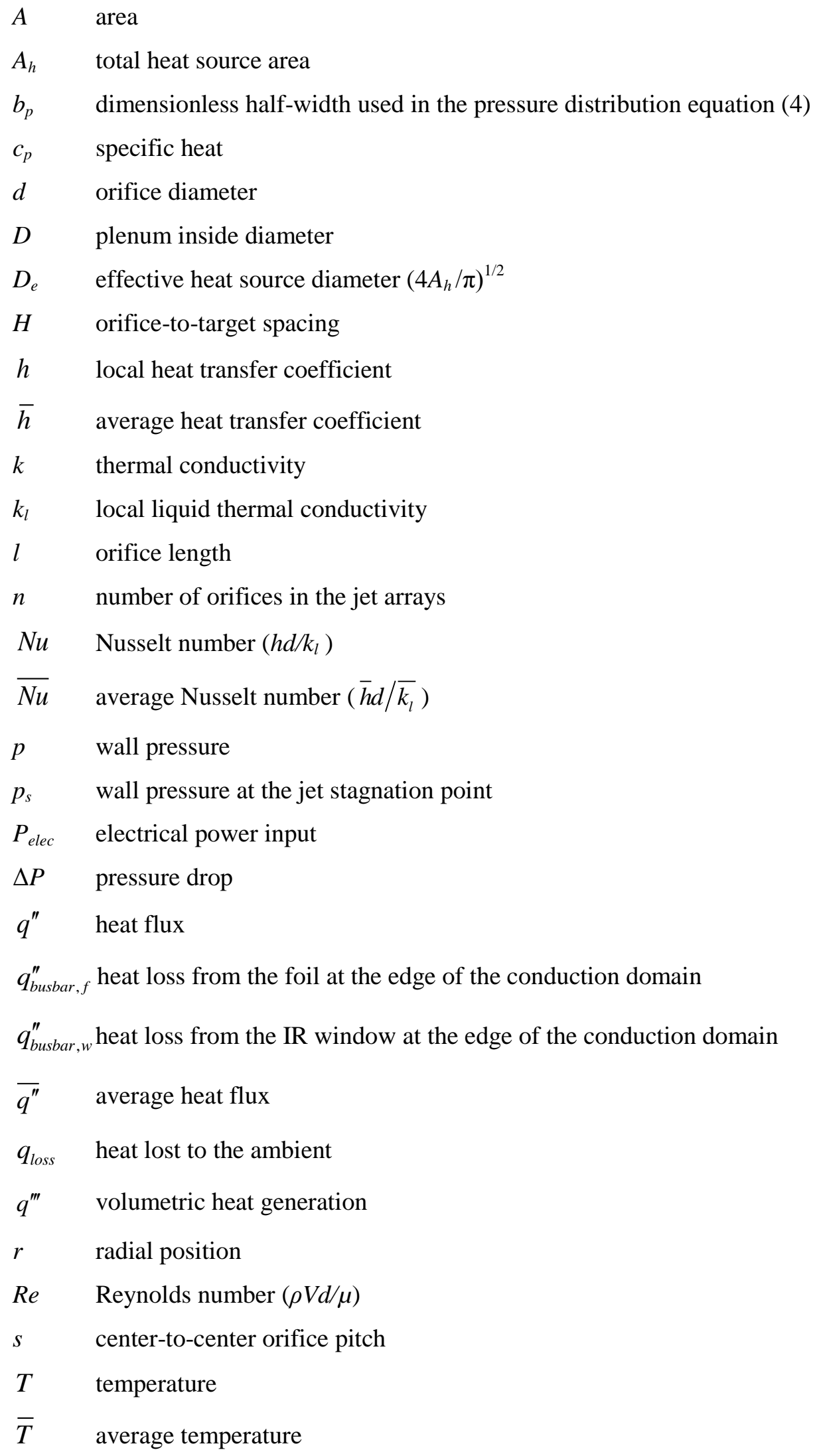


$T_{j} \quad$ jet inlet temperature

$V \quad$ jet velocity

\title{
Greek Symbols
}

$\mu \quad$ dynamic fluid viscosity

$\rho \quad$ fluid density

$\beta \quad$ orifice contraction ratio $\left(n d^{2} / D^{2}\right)$

\author{
Subscripts \\ $i \quad$ pixel value \\ $o \quad$ stagnation point value \\ sat saturation temperature \\ $l \quad$ liquid property \\ $\infty \quad$ bulk fluid property in test section chamber
}

Keywords: jet impingement, two-phase cooling, boiling, infrared thermography, pressure drop, HFE7100

\section{Introduction}

The continuing need for handling the high heat fluxes generated by electronic components used in a variety of applications has driven the sustained research in jet impingement. The design flexibility inherent to jet impingement makes it an attractive practical option for applications including automotive power electronics cooling, where large-area devices (of approximate $1-2 \mathrm{~cm}^{2}$ size) must be cooled in a compact space and existing dedicated cooling loops may be exploited. When designed for a low pressure drop, two-phase jet impingement may help bridge the gap between the capacity of current single-phase cooling technologies and future performance demand.

Liquid impinging jets are classified as submerged when they issue into an environment that is completely filled with the working fluid (in contrast to a free-surface liquid jet that issues into an ambient gas phase). In confined jet impingement, the working fluid is confined between an orifice plate and the impingement surface, forcing flow from the jets to escape radially outward in a narrow gap. The performance characteristics of single-phase submerged and confined jets are well-documented in the literature [1], and performance trends with respect to parametric variations in orifice diameter, orifice-totarget spacing, and Reynolds number are well-understood. The local heat transfer coefficient from a submerged and confined jet is typically characterized by a bell-shaped distribution, decreasing in the 
outward radial direction from a primary peak at the jet stagnation point. Inflection points in the bellshaped distribution are attributed to transition to turbulence and toroidal recirculation that occur at an approximate radial position of 1.9 jet diameters. The inflections may grow into secondary peaks in the distribution with increasing jet Reynolds number and decreasing orifice-to-target spacing [2].

In two-phase confined and submerged jet impingement, the working fluid is allowed to boil over the heated surface. As a potential cooling technology, two-phase jet impingement has a number of advantages over single-phase forced convection and passive boiling approaches. The added change of phase offers significant enhancement in heat transfer compared to single-phase jets, and active purging of vapor by the impinging flow can extend critical heat flux (CHF) significantly compared to pool boiling $[3,4]$.

The inherently non-uniform heat transfer coefficient distribution under impinging jets points to the importance of careful characterization with local measurement techniques. The local heat transfer coefficient may be deduced by measuring the local temperature of a thin-foil heat source in which there is minimal lateral spreading. The understanding of single-phase jet impingement heat transfer, in particular, has benefited from numerous studies using local temperature measurements. Ma and Bergles [5] studied the effect of orifice-to-target spacing $(H / d)$ and Reynolds number $(R e)$ on the local surface heat transfer profiles for a single, submerged and unconfined jet of the refrigerant R-113 (with orifice diameter $d=$ $1.067 \mathrm{~mm}$ ). To measure local temperature, the heat source was instrumented with a single thermocouple and moved laterally relative to the impinging jet. Similar approaches were used by Garimella and coworkers $[2,6]$ to measure the local heat transfer from single, submerged and confined jets of the perfluorinated dielectric liquid FC-77, and from confined air jets (single and arrays) [7, 8, 9]. Heat sources instrumented with arrays of thermocouples have also been used to measure local temperatures $[10,11,12]$; however, the spatial resolution of this technique is limited by the practical size and pitch of the thermocouple beads.

To improve upon the resolution of local temperature measurements, image-based thermographic techniques have been deployed. Huber and Viskanta [13] imaged a calibrated thermochromic liquid crystal coating layer to determine the local temperatures of a thin-foil heat source cooled by arrays of confined air jets. Infrared (IR) thermography is also a natural choice for resolving the spatial temperature distribution under impinging jets. Webb and coworkers $[14,15]$ imaged a thin, stainless-steel foil heat source, tightly stretched between two electrical bus-bars, with an IR camera to study the local heat transfer under free-surface liquid jets and jet arrays. Similar techniques have been used to study unconfined air jets by Lytle and Webb [16], Peper et al. [17], and Katti and Prabhu [18] and piezofans by Kimber et al. [19]. Patil and Narayanan [20] studied microscale air jet impingement via IR imaging of a heat source backed by an IR-transparent window. 
While single-phase jet impingement has been locally characterized in the aforementioned studies, local heat transfer measurements for two-phase jet impingement are comparatively scarce. Vader et al. [21] used an array of thermocouples to study nucleate boiling on a heated strip cooled by a free-surface planar jet of water. They showed that the transition to a turbulent boundary layer is strongly affected by bubble nucleation. Within the wall jet downstream of the stagnation point, the onset of nucleate boiling (ONB) occurred just upstream of the point of turbulent transition in the developing boundary layer where the wall temperature was at its maximum. Once ONB occurred, the transition to turbulence (and location of incipient bubble nucleation) progressively moved inward toward the stagnation point of the jet with increasing heat flux. In a similar study, Wolf et al. [22] showed a large streamwise variation in the local heat transfer coefficient for their free-surface planar water jet. Based on the local hydrodynamics, they concluded that the magnitude of single-phase and partial boiling heat transfer coefficient depends heavily on position relative to the impinging jet; however, fully developed boiling heat transfer was largely insensitive to both the position and convective bulk flow. In a study that used thermocouples to make seven discrete local temperature measurements, Shin et al. [23] showed that the local heat transfer depended heavily on the orifice-to-target spacing for a confined, planar jet of dielectric liquid, even in fully developed nucleate boiling.

Few studies have obtained comprehensive surface temperature distributions under two-phase jet impingement. Dukle and Hollingsworth $[24,25]$ used a thin-foil heat source, resistance temperature detectors at three different radial locations, and thermochromic liquid crystal paint to determine local heat transfer from a single submerged, unconfined circular jet of refrigerant R-11. They investigated the interaction between the position of boiling incipience (termed the boiling front) and the local single-phase convection for two orifice-to-target spacings $(H / d)$ that yielded a monotonic convection coefficient distribution $(H / d=8.2)$ and a non-monotonic convection coefficient distribution $(H / d=2.3)$. It was concluded that boiling and single-phase convection could coexist over the heated surface at all heat fluxes following incipience due to the stabilizing effect of a monotonic radial temperature gradient. When flow geometry dictated a non-monotonic temperature gradient along the heated surface, however, the boiling front remained stable with increasing heat flux only until it progressed inward to the secondary peak in heat transfer. At this point, the entire remaining heated area instantaneously transitioned to a boiling regime.

The relative pumping power performance of different orifice configurations in two-phase impingement must also be characterized. The pressure drop across single-phase orifices has been investigated [26]; however, pressure drop trends for two-phase impinging round jets and jet arrays remain unexplored. 
Despite the abundance of the available jet-impingement literature, guidelines for the choice of optimal two-phase orifice geometries are not available. Detailed measurements of local nucleate boiling heat transfer coefficients with two-phase jets are also uncommon, and are virtually nonexistent for arrays of round orifices. The present study investigates submerged and confined two-phase jet impingement for orifice array geometries and a heat source size that would be typical of power-electronics cooling applications. The two-phase heat transfer and pressure drop resulting from a single, round orifice and two different orifice arrays, all having the same total open orifice area, are quantified and compared. Excellent spatial resolution of the surface temperature measurements is ensured via IR thermography of a thin-foil heat source. Three different volumetric flow rates are investigated at a single orifice-to-target spacing, and the local heat transfer characteristics resulting from each orifice type are discussed.

\section{Experimental Setup}

\subsection{Flow loop}

A schematic diagram of the experimental facility flow loop is shown in Figure 1. The dielectric liquid HFE-7100 (3M, $k_{l}=0.069 \mathrm{~W} / \mathrm{mK}, \rho=1481 \mathrm{~kg} / \mathrm{m}^{3}, c_{p}=1183 \mathrm{~J} / \mathrm{kgK}, \mu=5.63 \times 10^{-4} \mathrm{~kg} / \mathrm{ms}$ at $25^{\circ} \mathrm{C}$, $T_{\text {sat }}=61{ }^{\circ} \mathrm{C}$ at atmospheric pressure [27]) is circulated through the closed loop by a magnetically coupled gear pump. Downstream of the pump, a test-section bypass line is included in the flow loop that allows for fine adjustment of the flow rate through the test section with a metering valve, independent of pump speed. The test section flow rate is measured by one of two turbine flowmeters (S-114, McMillian) with ranges of $100-1000 \mathrm{ml} / \mathrm{min}$ and $500-5000 \mathrm{ml} / \mathrm{min}$. Before entering the test section, the fluid is preheated to the desired subcooling with a temperature-controlled inline heater. After exiting the test section, the fluid is cooled by a liquid-to-air heat exchanger and returned to the reservoir. The custombuilt expandable reservoir in the facility allows for fluid degassing and precise control of the system operating pressure while maintaining a closed flow loop. The expandable reservoir design is explained in detail in [28]. The loop flow lines are constructed from $3 / 8$ inch $(9.5 \mathrm{~mm})$ stainless steel tubing throughout, except between the test section and the reservoir, where 1/2 inch $(12.7 \mathrm{~mm})$ tubing was used to minimize the pressure drop between the test section and reservoir at high flow rates.

Two filters are installed in the flow loop to ensure that the fluid is free of particulates and contaminants. A $40 \mu \mathrm{m}$ particulate filter is placed in series with the flow loop, downstream of the pump. Hydrofluoroether (HFE) fluids have a high affinity for oils from certain rubber and plastic materials. These contaminants have been shown to decrease the two-phase performance of the fluid; however, treatment with activated carbon can restore the fluid to its original cleanliness and performance [29]. Hence, a carbon filter (12011 Carbon Capsule, Pall) is added to the flow loop to remove oils and 
plasticizers from the fluid between tests. Use of silicone rubbers and fluorinated materials in the facility is also avoided to the extent possible, due to their poor compatibility with HFE-7100.

\subsection{Test section}

The submerged two-phase jet impingement test section is shown in Figure 2. The test section accommodates a wide range of test parameters, including different orifice geometries, orifice-to-target spacings, flow rates, and different heat sources. The test section components are made from polyether ether ketone (PEEK) to minimize heat losses to the environment, or polycarbonate in cases where optical access is desired. The bottom of the test section chamber and the four walls are permanently sealed with epoxy and sealant, while the top of the test section is removable and sealed with a butyl rubber gasket. Fluid enters through the top of a cylindrical jet plenum and flows through two screens and one honeycomb flow conditioner to ensure uniform flow just upstream of the orifice plate. Interchangeable PEEK orifice plates are mounted to the bottom of the plenum. A single fluid outlet is located at the top of the test section chamber; this, however, does not influence the radial uniformity of the jet outflow in the confinement gap due to the comparatively large fluid volume in the test section chamber.

A translating o-ring seal between the plenum outer diameter and the top wall of the test section provides plenum height adjustability relative to the main test section body. The orifice-to-target spacing is set by three precision-machined stainless steel spacing pins, which also ensure that the orifice plate and the heat source are aligned. The pins ( $2.38 \mathrm{~mm}$ in diameter) are located at the furthest extent possible from the center of the plenum to avoid interference with the jet outflow. Once positioned, the plenum is bolted and pressed tightly against the spacing pins to maintain the precise confinement gap desired throughout the test.

The plenum is instrumented with a T-type thermocouple located just upstream of the orifice plate to measure the jet inlet fluid temperature. A differential pressure transducer (PX2300-2DI, Omega) with a 0 $-13.8 \mathrm{kPa}$ range measures the pressure drop between two $1.6 \mathrm{~mm}$ diameter taps, located just upstream of the orifice plate and along the bottom wall of the test section chamber as shown in Figure 2. The gage pressure within the test section is measured via the same pressure tap in the bottom wall with a $0-103$ $\mathrm{kPa}$ range pressure transducer (PX302-015GV, Omega) and the bulk fluid temperature within the chamber is measured with an additional T-type thermocouple. All thermocouples are referenced to a dryblock ice point reference (TRCIII, Omega) and have an absolute uncertainty of $\pm 0.3{ }^{\circ} \mathrm{C}$. All pressure transducers are precisely calibrated (Pascal 100, Scandura) before installation, yielding uncertainties in the pressure measurements of $\pm 0.01 \mathrm{kPa}$ for the differential transducer and $\pm 0.13 \mathrm{kPa}$ for the gage pressure transducer. 


\subsection{Thin-foil heat source}

Obtaining highly resolved local temperature distributions using IR thermography in the study of twophase jet impingement of a dielectric liquid introduces several challenges. Free-surface, single-phase water jets in the literature $[14,15]$ were configured to impinge upwards onto a heated foil, allowing the spent fluid to be collected by gravity in an open settling tank positioned below. A similar arrangement in the current study would introduce air into the degassed working fluid (which has a very high affinity for absorbing air with a solubility of up to 53\% by volume at 1 atm [27]) and also allow a significant amount of the HFE-7100 to evaporate due to its high volatility. Instead, the entire fluid flow path in the present case must be sealed to ensure that all of the liquid and vapor is collected and recirculated, while leaving the back of the foil heat source exposed for infrared imaging. Complete sealing of the flow path demands that the thin foil heat source also provide structural integrity to withstand the impingement and any elevated flow pressure within the test section. To achieve this experimental objective, the foil heater is backed by an infrared-transparent magnesium fluoride $\left(\mathrm{MgF}_{2}\right)$ window, as illustrated in Figure 3a. A 20 $\mathrm{mm}$ wide, $50 \mu \mathrm{m}$ thick strip of 304 stainless steel $(k=16.3 \mathrm{~W} / \mathrm{mK})$ is soldered $(96.5 \% \mathrm{Sn}, 3.5 \% \mathrm{Ag}$, Indium Corp) between two copper bus bars to create a $20 \mathrm{~mm} \times 20 \mathrm{~mm}$ resistive-heating element. The copper bus bars are shaped to avoid optical obstruction of the foil from the camera angle of view below, while also providing adequate cross-sectional area for the required electrical current flow for the experiments (upwards of 100 amps) without themselves undergoing resistive heating. Two voltage taps soldered to the bus bars just below the foil provide a voltage drop measurement across the heat source. A DC power supply (DCR 7-300B, Sorensen) and 4 AWG cables supply the necessary electrical current, which is measured using a $0.667 \mathrm{~m} \Omega$ shunt resistor.

This foil-heat source assembly is mounted within a rectangular hole cut into a circular PEEK plate, which holds the foil taut and flush with the top surface of the plate. The PEEK plate insulates the heat source and is mounted flush with the inner surface of the test section bottom wall. A $1 \mathrm{~mm}$-wide chamfer in the PEEK housing around the perimeter of the stainless steel foil accommodates a thin bead of silicone sealant to create a leak-tight fluid seal to the PEEK plate, as shown in Figure 3a. The cured sealant is nearly flush with the impingement surface with a slight protrusion of the order of $100 \mu \mathrm{m}$, compared to the minimum orifice-to-target spacing $H$ of $3 \mathrm{~mm}$.

A $2 \mathrm{~mm}$-thick, square $\mathrm{MgF}_{2}$ infrared-transparent window is held in direct contact with the foil heat source by two lower brackets, each supporting a $1 \mathrm{~mm}$ wide strip along the backside edge of the window. Multiple infrared window materials were considered, including more thermally insulating thermoplastics, which were ultimately rejected due to the glass-transition temperatures of these materials being below the maximum heater temperatures expected in this study. The $\mathrm{MgF}_{2}$ window material is durable and temperature-resistant, and has a low thermal conductivity $(k=14.5 \mathrm{~W} / \mathrm{mK})$ compared to alternative 
crystalline materials. Prior to installation of the window, a highly emissive coating (HiE-Coat 840-M, Aremco) is applied to the back of the stainless steel foil to maximize the measurement sensitivity of the infrared thermography. This coating has an emissivity greater than 0.9 , is made specifically for stainless steel surfaces, has a low curing temperature $\left(93^{\circ} \mathrm{C}\right)$, and can withstand operating temperatures up to 1090 ${ }^{\circ} \mathrm{C}$. The higher curing temperatures necessary for heat-resistant paints precluded their use in this application. The back of the heat source assembly, including the window support brackets, $\mathrm{MgF}_{2}$ window, and the black emissive coating, is shown in Figure 4.

\subsection{Experimental procedures}

To collect local temperature data, an infrared camera (SC 7500, FLIR) is positioned below the test section and views the emissive-coating side of the foil heater through the infrared window. From the data reduction analysis presented in section 2.5 , the temperature difference between the imaged bottom side of the foil and the top surface is determined to be less than the overall temperature uncertainty, and is neglected. The camera is focused on the foil and then positioned using three micrometer stages to fill the field of view with only the heater foil surface. The camera views a $13.66 \mathrm{~mm} \times 17.08 \mathrm{~mm}$ area of the heater foil (ultimately cropped to $12 \mathrm{~mm} \times 12 \mathrm{~mm}$ ), resulting in a resolution of approximately $53 \mu \mathrm{m}$ per pixel.

An in-situ, pixel-by-pixel calibration is performed to remove the effects of emissivity irregularities in the coating, and temperature-dependent optical properties of the infrared window, on the final temperature measurements. To accomplish this calibration, the top of the test section chamber and jet plenum are removed, creating an open tank above the foil heat source. A temperature-controlled immersion circulator (HAAKE DC10, Thermo Electron Corp.) is lowered into the test section chamber that is filled with a calibration liquid. HFE-7500 is used as the calibration liquid (rather than the HFE7100 used in the tests) because its higher boiling point of $128^{\circ} \mathrm{C}$ allows for camera calibration over the entire temperature range of interest. The immersion circulator maintains a constant fluid temperature within the test section. Three additional T-type thermocouples are added to the pool (including one located $1 \mathrm{~mm}$ above the center of the foil surface) to record the liquid temperature and ensure uniformity. A temporary lid covers the test section to prevent excessive fluid evaporation during calibration. The test heater is not powered during calibration; therefore, the stainless steel temperature is assumed to be equal to that of the liquid in the chamber as measured by the thermocouple measurement located $1 \mathrm{~mm}$ above the center of the foil surface. Similar in-situ infrared camera calibration techniques have been used in the literature, although some have relied on a heated liquid jet for providing the reference temperature for calibration [14,15]. 
One hundred images are acquired over 10 seconds under steady-state conditions and averaged for eleven fluid temperatures between $40{ }^{\circ} \mathrm{C}$ and $100^{\circ} \mathrm{C}$ to build individual calibration curves for each camera pixel. The calibration curves are calculated by fitting a $4^{\text {th }}$ order polynomial to the digital output of each pixel as a function of heater temperature. Based on the uncertainty of the calibrated thermocouple readings $\left( \pm 0.3{ }^{\circ} \mathrm{C}\right)$, the standard deviations of the pixel-level digital signals over time, and the variances and covariances of the fitted parameters in the $4^{\text {th }}$ order calibration curves (calculated from a regression analysis), the uncertainty of the calibrated IR surface temperature measurements is estimated to range from $\pm 0.3{ }^{\circ} \mathrm{C}$ to $\pm 0.4{ }^{\circ} \mathrm{C}$. Application of the calibration curves and non-uniformity correction to the experimental images is performed in a post-processing MATLAB [30] code. As with calibration, one hundred images are acquired over ten seconds at steady state and averaged for each experimental data point. A frame rate of $10 \mathrm{fps}$ and an integration time of $500 \mu \mathrm{s}$ are used for both calibration and the acquisition of experimental thermal images.

After calibration of the infrared camera, the test section is reassembled as shown in Figure 2 for experimentation. The HFE-7100 working fluid is first degassed using a vacuum pump connected to the expandable reservoir. More details on the degassing procedure are provided in [28]. The fluid can only be degassed in batches with the reservoir isolated from the test section as the test section seals cannot support vacuum pressures. The fluid is therefore circulated between batches to remove non-condensable gases from all the fluid within the system. Prior to each test, the stainless steel heat source is also powered up to remove any air entrapped in surface nucleation sites. Once completely degassed, the fluid is pumped through the flow loop at a constant flow rate and heated by the inline heater to an inlet subcooling of $10{ }^{\circ} \mathrm{C}$, with the bulk fluid saturation temperature $\left(T_{\text {sat, },}\right)$ being calculated based on the measured pressure in the test section chamber. To mitigate an increase in system pressure experienced during testing due to thermal expansion of the working fluid, a slight positive pressure is initially maintained in the expandable reservoir (approximately $20 \mathrm{kPa}$ above atmospheric), and slowly relieved during testing to allow for constant-pressure operation. To run an experiment, the power to the heat source is increased in steps and steady-state data, including thermal images, are recorded at each heat flux. Critical heat flux (CHF) is carefully avoided to prevent damage to the foil heat source. In most of the cases presented, the heat flux was increased until a small amount of film boiling was evident on the edge of the heated surface (indicated by infrared camera pixel saturation), beyond which point the experiment was discontinued.

The single round orifice (diameter $d=3.75 \mathrm{~mm}$ ), the $3 \times 3$ array of round orifices $(d=1.25 \mathrm{~mm}$ ), and the $5 \times 5$ array of round orifices $(d=0.75 \mathrm{~mm})$ are shown for comparison in Figure $3 \mathrm{~b}$. The diameters of the orifices are chosen such that the total open flow area of each geometry remained identical. This results in a constant mass flux through each orifice plate and a constant mean jet velocity for all orifices at 
a given volumetric flow rate. The orifice plate thickness $l$ is chosen such that the orifice aspect ratio $l / d$ is the same in all cases, and takes a value of 2; Morris and Garimella [26] showed that a minimum in pressure drop across a sharp-edged orifice occurred at this value. The jet pitch ( $s$, shown in Figure $3 b$ ) for the two arrays is also kept constant at $s / d=4$ for reasonable coverage of the heat source by each array. The orifice-to-target spacing $(H)$ for each orifice geometry is varied to maintain a constant dimensionless spacing of $H / d=4$ ( $H$ ranging from $15 \mathrm{~mm}$ to $3 \mathrm{~mm}$ ). A dimensionless spacing of 4 is chosen so that $H$ did not exceed the potential core length of the jets, which has been shown to vary between 4 and 5 diameters for thin, sharp-edged orifices [2]. The experiments are conducted at three flow rates, 450, 900, and $1800 \mathrm{ml} / \mathrm{min}$, resulting in Reynolds numbers ranging from 1920 to 39400.

\subsection{Data reduction}

Two different reference temperatures are used in the data reduction and subsequent presentation of results. Boiling is typically referenced against the local saturation temperature as $\Delta T_{\text {sat }}=T-T_{\text {sat }}$, while single-phase convection is referenced against the jet inlet temperature as $\Delta T=T-T_{j}$. The boiling curves presented in this work employ $\Delta T_{\text {sat }}$, while the local heat transfer coefficient $h$ is defined as $h=\frac{q_{i}^{\prime \prime}}{\left(T_{i}-T_{j}\right)}$

where $q_{i}^{\prime \prime}$ is the local heat flux to the fluid, $T_{i}$ is the temperature measured by each camera pixel and $T_{j}$ is the jet inlet temperature. The use of these two reference temperatures is consistent with the typical practice in the literature (e.g., [22]). Additionally, because experiments are performed at a constant inlet subcooling, $T_{j}$ is always $10^{\circ} \mathrm{C}$ less than $T_{s a t, \infty}$, facilitating direct comparison across all test cases.

Although a resistively heated foil approximates a constant heat flux boundary, heat spreading into the infrared window, which is appreciable because of its comparable thermal conductivity relative to the metal foil, complicates the calculation of local heat flux to the fluid, $q_{i}^{\prime \prime}$. While the need to account for lateral heat spreading has been discussed in the literature [31, 32], 3D heat spreading within the window backing must also be accounted for in the current study. A data reduction procedure, the results of which are validated against the literature in section 3.1, is implemented that takes into account the complexity of the heat source and IR window backing assembly. A 3D conduction heat spreading model is solved in FLUENT [33] to calculate the net local heat flux to the fluid at each pixel. Figure 5 shows a representation of the simulation domain. To perform the data reduction, the experimental infrared images are first converted to temperature maps by applying the pixel-by-pixel calibration. Temperature maps are smoothed using a Gaussian filter to eliminate small-amplitude noise across the images that can create large and unphysical temperature gradients between pixels. The smoothed $2 \mathrm{D}$ temperature maps are then 
imposed as the top boundary condition for the 3D heat conduction domain shown in Figure 5. This 3D domain simulates conduction in the heated portion of the stainless steel foil and the $\mathrm{MgF}_{2}$ window that are within the field of view (FOV) of the camera. The domain is meshed uniformly so that there is one boundary cell for each camera pixel (248 by 312 pixels after cropping), one cell through the stainless steel foil thickness, and eight cells through the infrared window thickness. Mesh-independence was checked against a trial calculation using five cells for the foil thickness, and the resulting local heat flux values were found to be within $0.2 \%$ of those calculated with one cell through this thickness. Natural convection to air is applied as the boundary condition on the bottom of the $\mathrm{MgF}_{2}$ window, while the two edges of the heat source assembly close to the PEEK insulation are assumed adiabatic. An outward heat flux boundary condition unique to each experimental heat input is applied to the final two lateral sides, and was determined from a separate 2D FLUENT simulation of the entire foil/window/bus bar assembly. The 2D computational domain is representative of the heater assembly in cross section, as shown in Figure 3a, where the PEEK is assumed to provide adiabatic insulation. This separate $2 \mathrm{D}$ simulation calculates the heat leaving the FOV through the foil thickness $\left(q_{b u s b a r, f}^{\prime \prime}\right)$ and IR window $\left(q_{b u s b a r, w}^{\prime \prime}\right)$ as a result of the copper bus bars, which act as large fins conducting some heat away from the heat source. A natural convection condition $\left(h=6 \mathrm{~W} / \mathrm{m}^{2} \mathrm{~K}\right)$ is applied to the bus bar and window boundaries exposed to the ambient, and a forced convection condition $\left(h=200 \mathrm{~W} / \mathrm{m}^{2} \mathrm{~K}\right)$ is applied to the small, unheated area of the stainless steel foil exposed to the liquid at the top of the bus bars. The $h$ values used for these boundary conditions are estimated based on expected fluid velocities and single-phase heat transfer correlations [34]. The sensitivity of the final processed results, presented later in this paper, on these boundary conditions is found to be negligible based on a sensitivity analysis.

Once the boundary conditions for the 3D conduction domain are determined, the volumetric heat generation in the stainless steel domain is imposed based on the experimentally measured electrical power dissipation, assuming uniform heat generation. Because the infrared-transparent window is simply held in contact with the stainless steel foil and a thin emissive coating layer is also present at this interface, a contact resistance between the foil and window is needed in the model. This contact resistance value is determined by performing a natural convection experiment in the facility test section chamber with the jet plenum removed. To deduce the contact resistance from the measurements, a known natural convection heat transfer coefficient for the upper surface of a hot plate (equation 9.30 in [34]) is imposed as the boundary condition on the top of the foil in the 3D FLUENT model described above. The value of contact resistance in the model is then varied iteratively until the experimentally obtained foil temperatures match the corresponding values in the model. The value obtained from this analysis, $30 \times$ $10^{-4} \mathrm{~m}^{2} \mathrm{~K} / \mathrm{W}$, includes the contact resistance and the resistance of the emissive coating, and is input into the model as an infinitesimally thin resistive layer. 
With all boundary conditions thus defined, the local heat flux leaving the top of the foil heat source is computed and read into MATLAB for the final data reduction. The local heat flux and temperature maps are cropped to their final $12 \mathrm{~mm} \times 12 \mathrm{~mm}$ areas to exclude any edge effects caused by the conduction model and boundary conditions. The local heat flux values obtained from the simulation are summed to obtain the net heat flux to the fluid. The amount of heat lost through the window and bus bars typically ranges from $7-15 \%$ and is calculated according to

$q_{\text {loss }}=P_{\text {elec }}-\sum q_{i}^{\prime \prime} \times A_{i}$

where $P_{\text {elec }}$ is the electrical power dissipation in the area viewed by the infrared camera and $\mathrm{A}_{\mathrm{i}}$ is the area of one pixel.

The local heat transfer coefficient data are averaged in three different ways for presentation of results. The overall area-averaged heat transfer coefficient, which is useful in comparing the performance of the different orifice geometries and with results from the literature, is determined by

$$
\bar{h}=\frac{\sum q_{i}^{\prime \prime}}{\sum\left(T_{i}-T_{j}\right)} .
$$

Single jet results are also presented as radial averages, where $h$ is averaged around concentric radial annuli four pixels in width each, with the radial position denoted by the annulus half-width. It is noted that these annuli become fragmented towards the edges of the square heat source. Lastly, the results for the jet arrays are presented along diagonal rays as averages of four pixels at each point along the ray. Taking advantage of symmetry within the arrays, these points along the diagonals are then averaged over all four quadrants.

The jet Reynolds number is calculated using fluid properties at the jet inlet temperature, $T_{j}$, while the Nusselt numbers are calculated using fluid properties evaluated at the local film temperature on the heated surface (calculated as the arithmetic average of the pixel temperature $T_{i}$ and the jet temperature $T_{j}$ ).

The change in local wall pressure, and therefore in the local liquid saturation temperature, can have an important effect on the reported local two-phase jet impingement heat transfer coefficients. It has been shown in the literature that the wall pressure beneath an impinging jet reaches its maximum at the stagnation point and then decays in a Gaussian-like distribution [35, 36, 37]. The stagnation point value can be represented by $p_{s}=\rho V / 2$ for orifice-to-target spacings that are within the potential core length of the jet [38]. Similar to the local saturation temperature calculations performed in [39], the local saturation temperature along the wall of the heated surface is calculated from a local pressure distribution [38], which is taken as 


$$
\frac{p}{p_{s}}=\exp \left(-\ln (2)\left(\frac{r / d}{b_{p}}\right)^{2}\right)
$$

where the dimensionless half-width, $b_{p}=0.61$, is chosen based on data from [36,37]. In the case of the jet arrays, the square area under each jet is treated as a unit cell (as shown in Figure $3 b$ ) and the pressure distribution is computed as if each of the jets in the array is isolated. The maximum jet velocity tested in this study $(\sim 2.72 \mathrm{~m} / \mathrm{s})$ results in a stagnation point pressure increase of approximately $5 \mathrm{kPa}$, which corresponds to a maximum local saturation temperature rise of $1.3{ }^{\circ} \mathrm{C}$ for the test fluid, HFE-7100.

Applying a standard uncertainty analysis [40] to the data reduction procedures above reveals an uncertainty in the local heat transfer coefficient ranging from $11 \%$ to $15 \%$ (using a 95 percent confidence interval). This uncertainty is dominated by the contribution of the foil thickness uncertainty, estimated to be $10 \%$ based on micrometer measurements of the thickness over many sampling points. The foil thickness uncertainty is introduced into the local heat flux calculation by the 3D spreading conduction simulation, for which the volumetric heat generation was a necessary input. Because the uncertainty in foil thickness dominated uncertainties in the other inputs to the model, the uncertainty in local heat fluxes was taken as $10 \%$. The other significant sources of error are the jet inlet (thermocouple) and IR surface temperature measurement uncertainties. These temperature uncertainty contributions are largest at low heat fluxes due to the small $\Delta T$ used to calculate the heat transfer coefficient, although their relative contribution quickly diminishes as $\Delta T$ increases at higher heat fluxes.

\section{Results and Discussion}

\subsection{Validation of single-phase heat transfer results}

To validate the measurement and data reduction techniques, single-phase results are compared against accepted correlations in the jet impingement literature. Experimentally obtained $N u_{o}$ values are shown as a function of $R e$ in Figure 6a. Stagnation data from the jet arrays are plotted for the central jet. The single-phase experimental stagnation Nusselt numbers are in good agreement with a correlation developed by Li and Garimella, equation 8 in [41]. This correlation was developed for single, confined and submerged impinging jets over a wide range of Prandtl numbers, and is applied for the current liquid properties in Figure 6a. The mean average error (MAE) between stagnation point experimental results and the correlation is $12.4 \%$, and this good match is of particular value for validation of the 3D conduction spreading calculation employed in the data reduction method. The net effect of accounting for heat spreading between hot and cold areas within the foil and infrared window is to amplify peaks and minimize valleys in the heat transfer coefficient. While the area-averaged Nusselt numbers are relatively unaffected, the stagnation values are sensitive to the spreading calculation. If the amount of heat 
spreading were over- or under-estimated, this agreement between the experimental and predicted $N u_{o}$ values would not be realized.

An average Nusselt number correlation developed by Li and Garimella, equation 18 in [41] is shown as a function of $R e$ in Figure 6b. This figure also includes the popular single-phase correlation for a single round orifice presented by Martin [42]. Excellent agreement (MAE $=1.3 \%$ ) is observed between the experimental single jet data and predicted values. This overall agreement lends further confidence to the measurement and data reduction techniques.

\subsection{Local heat transfer from impinging jets}

Temperature contour maps for all three jet configurations are shown in Figure 7 for a flow rate of 450 $\mathrm{ml} / \mathrm{min}$. From top to bottom, the figure shows temperature map data for the single jet, $3 \times 3$ array, and 5 $\times 5$ array at $\sim 4.5 \mathrm{~W} / \mathrm{cm}^{2}$ (Figure $7 \mathrm{a}$ ) and $\sim 12.0 \mathrm{~W} / \mathrm{cm}^{2}$ (Figure $7 \mathrm{~b}$ ). The temperature scale and contour line spacing $\left(1^{\circ} \mathrm{C}\right)$ is held fixed for ease of comparison across all maps. At $\sim 4.5 \mathrm{~W} / \mathrm{cm}^{2}$, boiling is not observed for any of the orifice geometries, and the single-phase temperature maps are characterized by symmetric temperature distributions around each impinging jet. In all cases, the coolest temperatures coincide with the stagnation points of the impinging jets. Figure $7 \mathrm{~b}$ shows the surface temperatures when boiling is observed on the heater foil, which occurs for all cases at $\sim 12 \mathrm{~W} / \mathrm{cm}^{2}$. In contrast to the singlephase regime, the two-phase temperature maps display small-scale temperature noise due to the local nucleate boiling heat transfer processes. The histograms of the temperature maps, shown in between the two columns of temperature maps in Figure 7, display the relative uniformity of temperature across the heated surface for each case. Each histogram presents the percentage of the heated surface that is at a given temperature. Two-phase heat transfer resulted in a more uniform surface temperature for the single jet, which is displayed by its sharper histogram. The total temperature range observed on the surface decreased from $T_{\max }-T_{\min }=9.9{ }^{\circ} \mathrm{C}$ in single-phase to $T_{\max }-T_{\min }=6.1^{\circ} \mathrm{C}$ in two-phase operation. Unlike the single jet, boiling in conjunction with the impinging jet arrays resulted in a larger range of surface temperatures $\left(T_{\max }-T_{\min }\right.$ increasing from $12.9^{\circ} \mathrm{C}$ to $13.6{ }^{\circ} \mathrm{C}$ for the $3 \times 3$ array and from $11.5^{\circ} \mathrm{C}$ to 16.2 ${ }^{\circ} \mathrm{C}$ for the $5 \times 5$ array), as also indicated by their wider histogram distributions. The arrays also result in higher surface temperature gradients, as is indicated by the closely spaced temperature contour lines around the stagnation points of the jets. While all histograms for $\sim 12 \mathrm{~W} / \mathrm{cm}^{2}$ show a peak at approximately $90{ }^{\circ} \mathrm{C}$, likely indicative of similar boiling heat transfer coefficients occurring on much of the surface at this heat flux, the temperature distributions of the jet arrays are still influenced by the single-phase convective impinging liquid jets; the single-phase axisymmetric temperature profile from the single jet is no longer discernible, but the circular pattern surrounding each impinging jet in both arrays is still clearly defined. This single-phase influence from the impinging jet arrays results in the higher non- 
uniformity in surface temperature shown at $\sim 12 \mathrm{~W} / \mathrm{cm}^{2}$. In contrast, the single jet displays more uniform surface temperatures due to its reduced single-phase performance, which allows more boiling to occur on the heated surface. This conclusion is more clearly demonstrated by interrogation of the local heat transfer coefficient data in the following.

In order to further understand the local convection and boiling contributions, heat transfer coefficient distributions and local boiling curves are presented. Convection coefficient profiles for the single jet, $3 \times$ 3 array, and $5 \times 5$ array are shown in Figure 8 . The convection coefficient profile is plotted as a function of non-dimensional distance from the center of the heat source for the full range of heat fluxes considered in each test (as indicated on the graphs). The y-axis range is unchanged among the plots for each orifice geometry to allow direct comparison across flow rates. All tests commence at a heat flux below that needed for the onset of nucleate boiling, and the lowest profile shown in each plot represents a purely single-phase heat transfer coefficient over the entire heater surface. Considering that the single-phase convection coefficient is known to be independent of applied heat flux (since natural convection effects are minimal), any local increase observed in the heat transfer coefficient profile is indicative of nucleate boiling at the location. Regions that collapse to a single curve indicate that single-phase heat transfer is sustained over the range of heat fluxes investigated.

At low heat fluxes, the convection coefficient profile for the single jet (Figure 8a) exhibits the singlephase bell-shaped distribution described in the literature $[1,2]$. Enhancement in $h$ due to boiling begins at large radial distances which experience low local flow velocities and moves closer to the stagnation point of the jet with increasing heat flux. This two-phase heat transfer enhancement is indicative of a stable boiling front that begins at large radii and moves inward with increasing heat flux, a trend that has been illustrated in the literature for impinging single round and slot jets [21, 22, 24]. Unlike the two lower flow rates, where the boiling front reaches $r / d=0$ at the highest heat flux, the upper heat flux for the 1800 $\mathrm{ml} / \mathrm{min}$ case is experimentally limited by film boiling at the heater edges prior to the boiling front reaching the stagnation point of the impinging jet.

The heat transfer coefficient profiles plotted along the diagonal of the heat source for the $3 \times 3$ and 5 $\times 5$ arrays, at flow rates of 450, 900, and $1800 \mathrm{ml} / \mathrm{min}$, are shown in Figure $8 \mathrm{~b}$ and Figure $8 \mathrm{c}$, respectively. The peaks in these profiles coincide with the stagnation points of the impinging jets in the array. The jet pitch used in this study $(s / d=4)$ equates to a diagonal center-to-center jet pitch of 5.66 diameters. Although each orifice in all of the orifice configurations had the same mean velocity at a given total volumetric flow rate, the respective heat transfer coefficient profiles show that the smaller orifices in the jet arrays resulted in higher-magnitude peaks in single-phase $h$. Higher stagnation point convection coefficients for smaller submerged and confined jets were also observed by [2,7], and this conclusion is also supported for other jet configurations in the literature. The dependence of heat transfer 
coefficient on jet diameter and velocity is implicit in the stagnation point Nusselt number which is generally correlated with the functional form given by

$$
N u_{o} \propto \operatorname{Re}^{m} f\left(\operatorname{Pr}, \frac{l}{d}, \frac{z}{d}, \frac{D_{e}}{d}\right),
$$

where $N u_{o}$ increases with increasing $R e$. The Reynolds number exponent in the literature has ranged from $m=0.44$ for fully developed free jets of water [11] to $m=0.5$ for submerged, unconfined jets of R-113 [5]; the correlation for confined and submerged liquid jets used in Figure 6a uses $m=0.497$. Solving for $h_{0}$ and $d$ in equation 5 results in $h_{o} \propto \frac{1}{d^{(1-m)}}$.

The stagnation point convection coefficient is inversely proportional to the jet diameter for a fixed jet velocity. Flow field measurements for confined and submerged impinging jets [43] show that the maximum turbulence in the impinging flow occurs at the jet periphery. Concentration of this orifice edge-generated turbulence over a smaller area could be one reason for the increase in $h_{o}$ with decreasing diameter.

As with the results for the single jet where boiling enhancement commenced at large radial distances from stagnation, boiling also occurred at locations furthest from the stagnation points in the jet arrays, initiating at the locations half-way between orifices. Enhanced heat transfer is observed in between the stagnation point peaks with increasing heat flux. Little enhancement is shown in the profiles with increasing heat flux for the jet arrays at $1800 \mathrm{ml} / \mathrm{min}$. This is likely due to an upper heat flux limit imposed by film boiling at the edge of the heat source, as the experiments were not continued to higher heat fluxes past this operational point. Enhanced heat transfer due to boiling towards the edge of the heat source is not apparent in the profiles in Figure $8 \mathrm{~b}$ and Figure $8 \mathrm{c}$ because the regions where this would occur lies outside the field of view of the IR camera.

Boiling curves at different radial locations for each orifice geometry are shown in Figure 9 for the 450 $\mathrm{ml} / \mathrm{min}$ flow rate. Figure 9a shows local boiling curves for the single jet which indicate that the onset of nucleate boiling occurs at a lower heat flux with increasing distance from the stagnation point. This plot also shows that fluid at the stagnation point of the jet $(r / d=0)$ transitions to boiling at approximately $q^{\prime \prime}$ $=11 \mathrm{~W} / \mathrm{cm}^{2}$, which is characterized by a sudden change in slope at this heat flux. Local boiling curves along the diagonal direction for the jet arrays at $450 \mathrm{ml} / \mathrm{min}$ (Figure $9 \mathrm{~b}$ and Figure $9 \mathrm{c}$ ) further indicate the difference in local heat transfer caused by the multiple impinging jets. These local boiling curves at the jet stagnation points and intermediate locations show considerable nonuniformity in the local heat transfer. Compared to the intermediate locations, the stagnation points of the jets show a steeper single- 
phase regime slope, indicative of superior single-phase heat transfer, but without an onset of nucleate boiling. Also, the distance of the stagnation point from the heat source center within the array appears to have a slight effect on the local heat transfer for the two arrays studied. The outer jet in the $3 \times 3$ array displays a boiling curve slightly shifted to a lower superheat compared to the central jet at $r / d=0$. The 5 $\times 5$ array, interestingly, shows a boiling curve shifted towards lower superheats at $r / d=5.6$, which corresponds to the stagnation point of the jet located between the center jet and outermost corner jet in the array. The slightly enhanced relative cooling at this location may point to favorable jet-jet interactions and crossflow effects that occur between jets towards the center of large jet arrays. For both the $3 \times 3$ array and $5 \times 5$ array, the area-averaged boiling curves are clearly poor representations of the local heat transfer.

Figure 10 shows the area-averaged boiling curves for all three orifices at 450 and $1800 \mathrm{ml} / \mathrm{min}$. The data for the $900 \mathrm{ml} / \mathrm{min}$ flow rate has been excluded for clarity (these results fall in between the lower and higher flow rates as expected). The arrays have superior single-phase performance and the $5 \times 5$ array consistently achieves the highest average heat fluxes for each flow rate tested. In combination with the above local heat transfer discussion, we conclude that the jet arrays in this investigation achieve superior area-averaged two-phase heat transfer performance at the expense of temperature uniformity. While the distribution of peaks in convection coefficient across the heated surface created by the jet arrays may be expected to produce a more uniform surface temperature distribution, the large, single jet actually achieves the highest degree of temperature uniformity due to the greater extent of boiling that occurs on the heated surface. The higher area-averaged heat transfer coefficient achieved with the jet arrays relative to single jets is largely due to their superior single-phase performance and the higher peaks in stagnation point convection coefficient for the jet arrays.

\subsection{Pressure drop}

To first validate the pressure drop measurements, single-phase pressure drop results were compared against a correlation from the literature. The pressure drop measured for the single jet is in good agreement $(\mathrm{MAE}=8.0 \%)$ with the pressure drop predicted by equation 3 in [26] over the Reynolds number range investigated as shown in Figure 11. The experimental pressure drop for all orifice geometries is shown as a function of heat flux in Figure 12 for all flow rates. Although all single- and two-phase data points are included in this figure, the pressure drop clearly remains independent of heat flux. This indicates that the overall confined jet pressure drop is dominated by the single-phase pressure drop across the orifice, and is largely independent of the two-phase flow in the confinement gap. The two-phase flow through the gap may contribute to the overall pressure drop at higher heat fluxes and narrower orifice-to-target spacings (lowest spacing in this study is $3 \mathrm{~mm}$ for the $5 \times 5$ array) than are 
investigated in this study. The pressure drop correlations developed for single-phase confined and submerged jets [26] may therefore still be applied as design tools for estimating the pressure drop, even in the presence of two-phase operation.

The single jet and $3 \times 3$ array have approximately the same pressure drop of $0.6 \mathrm{kPa}$ at the 450 $\mathrm{ml} / \mathrm{min}$ flow rate, while the $5 \times 5$ experiences a higher pressure drop of $0.7 \mathrm{kPa}$. Differences in the pressure drop between orifice geometries increase as the flow rate is increased. The $3 \times 3$ array resulted in the lowest pressure drop at $900 \mathrm{ml} / \mathrm{min}$ and $1800 \mathrm{ml} / \mathrm{min}(5.7 \%$ and $12.6 \%$ below that of the single jet, respectively), while the $5 \times 5$ array resulted in the highest pressure drop at these flow rates $(11.8 \%$ and $10.5 \%$ above the measured pressure drop for the single jet). Each orifice was inspected under a microscope and slight imperfections in the orifice outer diameters were observed. While very slight dimensional inaccuracies were also found, they were not significant enough to explain the differences on the order of $10 \%$ in the measured pressure drops. The pressure drop across a single, sharp-edged orifice is governed primarily by the jet velocity, $V$, and the orifice contraction ratio $\beta$ [26]. Because the flow area is held constant across orifice geometries, the jets have the same mean velocity at a given flow rate. The plenum inside diameter also remains unchanged at $35 \mathrm{~mm}$, resulting in a constant effective contraction ratio for all orifices of $\beta=0.01$. Furthermore, because the dimensionless orifice length in each configuration is kept constant at $l / d=2$, the fluid surface contact area is constant for all three geometries, which should result in the same amount of frictional pressure losses in each case. Given the evidence, the authors attribute the difference in pressure drop measured experimentally between the orifice geometries to the slight machining imperfections in the orifices.

\section{Conclusions}

Local heat transfer is characterized for two-phase confined and submerged jets of the dielectric fluid HFE-7100 via infrared (IR) thermography of a thin-foil heat source. Local boiling curves and heat transfer coefficients resulting from three different orifice geometries are presented: a single round orifice $(d=3.75 \mathrm{~mm})$, a $3 \times 3$ array of round orifices $(d=1.25 \mathrm{~mm})$, and a $5 \times 5$ array of round orifices $(d=0.75$ $\mathrm{mm})$. The results are obtained at three different flow rates $(450,900$, and $1800 \mathrm{ml} / \mathrm{min})$.

A specially designed thin-foil heat source backed by an IR-transparent window was fabricated, and a rigorous experimental procedure implemented to obtain high-spatial-resolution heat transfer measurements. In-situ IR thermography calibration, and careful data reduction that accounts for heat conduction spreading within the IR-transparent window, are necessary to obtain accurate local measurements. These data reduction procedures are validated against the single-phase jet impingement literature. The radial location on the heat source relative to the impinging jet stagnation points is shown to have a large effect on the local heat transfer. Locations far from the stagnation point of the single jet transition to nucleate boiling at lower heat fluxes, resulting in the coexistence of single- and two-phase 
heat transfer on different parts of the heated surface. With further increases in heat flux, the boiling fronts creep inward, and boiling eventually occurs over the entire surface at the lower flow rates investigated. The jet arrays result in superior single- and two-phase area-averaged heat transfer when compared to a single jet. As with the single jet, stable coexistence of single- and two-phase heat transfer is observed in between the arrays of impinging jets; however, single-phase convection dominated heat transfer in the stagnation region, resulting in an increased variation in local heat transfer across the surface compared to a single jet. While the jet arrays showed superior area-averaged cooling capability, their enhancement came at the expense of temperature uniformity.

The pressure drop in each orifice configuration is independent of the applied heat flux and two-phase vapor generation in the confined outflow region. The overall two-phase jet impingement pressure drop was concluded to be dominated by single-phase flow through the orifice, and largely unaffected by the two-phase flow in the confinement gap.

\section{Acknowledgements}

The authors thank Toyota Motor Engineering and Manufacturing North America, Inc., specifically Dr. Eric Dede and Dr. Shailesh Joshi, for their support and technical discussions related to this work.

\section{References}

1 S.V. Garimella, Heat transfer and flow fields in confined jet impingement, Annual Review of Heat Transfer 11 (2000) 413-494.

2 S.V. Garimella, R.A. Rice, Confined and submerged liquid jet impingement heat transfer, Journal of Heat Transfer 117(4) (1995) 871-877.

3 C.-F. Ma, A.E. Bergles, Boiling jet impingement cooling of simulated microelectronic chips, Heat Transfer in Electronic Equipment-1983, HTD-Vol. 28, 1983, pp. 5-12.

4 D. Copeland, Single-phase and boiling cooling of a small heat source by multiple nozzle jet impingement, Proceedings of the Winter Annual Meeting of the American Society of Mechanical Engineers, 1992, pp. 1-7.

5 C.-F. Ma, A.E. Bergles, Convective heat transfer on a small vertical heated surface in an impingement circular liquid jet, Proceedings of the Second International Symposium of Heat Transfer, 1988, pp. 248-255.

6 S.V. Garimella, B. Nenaydykh, Nozzle-geometry effects in liquid jet impingement heat transfer, International Journal of Heat and Mass Transfer 39(14) (1996) 2915-2923. 
7 V.P. Schroeder, S.V. Garimella, Heat transfer from a discrete heat source in confined air jet impingement, Proceedings of the Eleventh International Heat Transfer Conference, Kyongju, Korea, 1998, pp. $451-456$.

8 L.A. Brignoni, S.V. Garimella, Effects of nozzle-inlet chamfering on pressure drop and heat transfer in confined air jet impingement, International Journal of Heat and Mass Transfer 43(7) (2000) 11331139.

9 S.V. Garimella, V.P. Schroeder, Local heat transfer distributions in confined multiple air jet impingement, Journal of Electronic Packaging 123(3) (2001) 165-172.

10 S.J. Slayzak, R. Viskanta, F.P. Incropera, Effects of interaction between adjacent free surface planar jets on local heat transfer from the impingement surface, International Journal of Heat and Mass Transfer 37(2) (1994) 269-282.

11 J. Stevens, B.W. Webb, Local heat transfer coefficients under an axisymmetric, single-phase liquid jet, Journal of Heat Transfer 113(1) (1991) 71-78.

12 L.M. Jiji, Z. Dagan, Experimental investigation of single phase multi-jet impingement cooling of an array of microelectronic heat sources, Proceedings of the International Symposium on Cooling Technology for Electronic Equipment, Honolulu, HI, 1987, pp. 265-283.

13 A.M. Huber, R. Viskanta, Effect of jet-jet spacing on convective heat transfer to confined, impinging arrays of axisymmetric air jets, International Journal of Heat and Mass Transfer 37(18) (1994) 28592869.

14 Y. Pan, J. Stevens, B.W. Webb, Effect of nozzle configuration on transport in the stagnation zone of axisymmetric, impinging free-surface liquid jets: Part 2 - local heat transfer, Journal of Heat Transfer 114(4) (1992) 880-886.

15 Y. Pan, B.W. Webb, Heat transfer characteristics of arrays of free-surface liquid jets, Journal of Heat Transfer 117(4) (1995) 878-883.

16 D. Lytle, B.W. Webb, Air jet impingement heat transfer at low nozzle-plate spacings, International Journal of Heat and Mass Transfer 37(12) (1994) 1687-1697.

17 F. Peper, W. Leiner, M. Fiebig, Impinging radial and inline jets: A comparison with regard to heat transfer, wall pressure distribution, and pressure loss, Experimental Thermal and Fluid Science 14(2) (1997) 194-204.

18 V. Katti, S.V. Prabhu, Experimental study and theoretical analysis of local heat transfer distribution between smooth flat surface and impinging air jet from a circular straight pipe nozzle, International Journal of Heat and Mass Transfer 51(17-18) (2008) 4480-4495. 
19 M. Kimber, S.V. Garimella, A. Raman, Local heat transfer coefficients induced by piezoelectrically actuated vibrating cantilevers, Journal of Heat Transfer 129 (2007) 1168-1176.

20 V.A. Patil, V. Narayanan, Spatially resolved heat transfer rates in an impinging circular microscale jet, Microscale Thermophysical Engineering 9(2) (2005) 183-197.

21 D.T. Vader, F.P. Incropera, R. Viskanta, Convective nucleate boiling on a heated surface cooled by an impinging, planar jet of water, Journal of Heat Transfer 114(1) (1992) 152-160.

22 D.H. Wolf, F.P. Incropera, R. Viskanta, Local jet impingement boiling heat transfer, International Journal of Heat and Mass Transfer 39(7) (1996) 1395-1406.

23 C.H. Shin, K.M. Kim, S.H. Lim, H.H. Cho, Influences of nozzle-plate spacing on boiling heat transfer of confined planar dielectric liquid impinging jet, International Journal of Heat and Mass Transfer 52(23-24) (2009) 5293-5301.

24 N.M. Dukle, D.K. Hollingsworth, Liquid crystal images of the transition from jet impingement convection to nucleate boiling part I: Monotonic distribution of the convection coefficient, Experimental Thermal and Fluid Science 12(3) (1996) 274-287.

25 N.M. Dukle, D.K. Hollingsworth, Liquid crystal images of the transition from jet impingement convection to nucleate boiling part II: Nonmonotonic distribution of the convection coefficient, Experimental Thermal and Fluid Science 12(3) (1996) 288-297.

26 G.K. Morris, S.V. Garimella, Orifice and impingement flow fields in confined jet impingement, Journal of Electronic Packaging 120(1) (1998) 68-72.

27 3M, 3M Novec Engineered Fluid HFE-7100 for Heat Transfer, 3M, St. Paul, MN, 2002, pp. 1-8.

28 T. Chen, S.V. Garimella, Effects of dissolved air on subcooled flow boiling of a dielectric coolant in a microchannel heat sink, Journal of Electronic Packaging 128(4) (2006) 398-404.

29 P.E. Tuma, Design considerations relating to non-thermal aspects of passive 2-phase immersion cooling, Proceedings of the 27th Annual IEEE Semiconductor Thermal Measurement and Management Symposium, 2011, pp. 1 -9.

30 The MathWorks, Inc. MATLAB Version 7.14.0, Natick, Massachussetts, 2012.

31 J. Stafford, E. Walsh, V. Egan, Characterizing convective heat transfer using infrared thermography and the heated-thin-foil technique, Measurement Science and Technology 20(10) (2009) 1-11.

32 G.M. Carlomagno, G. Cardone, Infrared thermography for convective heat transfer measurements, Experiments in Fluids 49 (2010) 1187-1218.

33 ANSYS® FLUENT, Academic Research, Release 14.0

34 F.P. Incropera, D.P. Dewitt, T.L. Bergman, A.S. Lavine, Fundamentals of Heat and Mass Transfer, sixth ed., New York, 2007. 
35 S. Beltaos, N. Rajaratnam, Impinging circular turbulent jets, Journal of the Hydraulics Division 100(10) (1974) 1313-1328.

36 F. Giralt, C.-J. Chia, O. Trass, Characterization of the impingement region in an axisymmetric turbulent jet, Industrial and Engineering Chemistry Fundamentals 16(1) (1977) 21-28.

37 R.S. Amano, H. Brandt, Numerical study of turbulent axisymmetric jets impinging on a flat plate and flowing into an axisymmetric cavity, Journal of Fluids Engineering 106(4) (1984) 410-417.

38 C.V. Tu, D.H. Wood, Wall pressure and shear stress measurements beneath an impinging jet, Experimental Thermal and Fluid Science 13(4) (1996) 364-373.

39 D.W. Zhou, C.F. Ma, Local jet impingement boiling heat transfer with R113, Heat and Mass Transfer 40(6-7) (2004) 539-549.

40 P.R. Bevington, D.K. Robinson, Data reduction and error analysis for the physical sciences, second ed., McGraw-Hill, New York, 1992.

41 C.-Y. Li, S.V. Garimella, Prandtl-number effects and generalized correlations for confined and submerged jet impingement, International Journal of Heat and Mass Transfer 44(18) (2001) 34713480.

$42 \mathrm{H}$. Martin, Heat and mass transfer between impinging gas jets and solid surfaces, Advances in Heat Transfer 13 (1977) 1-60.

43 J.A. Fitzgerald, S.V. Garimella, A study of the flow field of a confined and submerged impinging jet, International Journal of Heat and Mass Transfer 41(8-9) (1998) 1025 - 1034. 


\section{List of Figures}

Figure 1. Flow loop schematic diagram.

Figure 2. Cross-sectional illustration of the jet impingement test section.

Figure 3. Illustration of (a) the thin-foil heat source assembly and (b) orifice geometries.

Figure 4. Photograph of the bottom of the heat source assembly. The black emissive coating is viewed through the MgF2 window, which is transparent in the IR and visible spectra.

Figure 5. Schematic illustration of the 3D conduction domain and boundary conditions used for local heat flux data reduction.

Figure 6. (a) stagnation point Nusselt numbers compared with equation 8 in [41], and (b) area-averaged Nusselt numbers compared with equation 18 in [41] and equation 4.10 in [42].

Figure 7. (a) Single-phase and (b) two-phase temperature maps with histograms (center) for the (from top to bottom) single jet, $3 \times 3$ array, and $5 \times 5$ array.

Figure 8. Heat transfer coefficient profiles for the (a) single jet $(\mathrm{d}=3.75 \mathrm{~mm}),(\mathrm{b}) 3 \times 3$ array $(d=1.25$ $\mathrm{mm})$, and (c) $5 \times 5$ array $(d=0.75 \mathrm{~mm})$ at flow rates of 450,900 , and $1800 \mathrm{ml} / \mathrm{min}$ for a range of heat fluxes.

Figure 9. Local boiling curves for (a) the single jet $(\mathrm{d}=3.75 \mathrm{~mm})$, (b) the $3 \times 3$ array $(d=1.25 \mathrm{~mm})$, and (c) the $5 \times 5$ array $(d=0.75 \mathrm{~mm})$ at a flow rate of $450 \mathrm{ml} / \mathrm{min}$.

Figure 10. Area-averaged boiling curves for the single jet $(\mathrm{d}=3.75 \mathrm{~mm}), 3 \times 3$ array $(d=1.25 \mathrm{~mm})$, and $5 \times 5$ array $(d=0.75 \mathrm{~mm})$ for flow rates of 450 and $1800 \mathrm{ml} / \mathrm{min}$.

Figure 11. Single-phase pressure drop for the single jet compared to equation 3 in [26].

Figure 12. Pressure drop for the single jet $(\mathrm{d}=3.75 \mathrm{~mm}), 3 \times 3$ array $(d=1.25 \mathrm{~mm})$, and $5 \times 5$ array $(d=$ $0.75 \mathrm{~mm}$ ) at flow rates of 450,900 , and $1800 \mathrm{ml} / \mathrm{min}$ as a function of heat flux. 




Figure 1. Flow loop schematic diagram. 




Figure 2. Cross-sectional illustration of the jet impingement test section. 


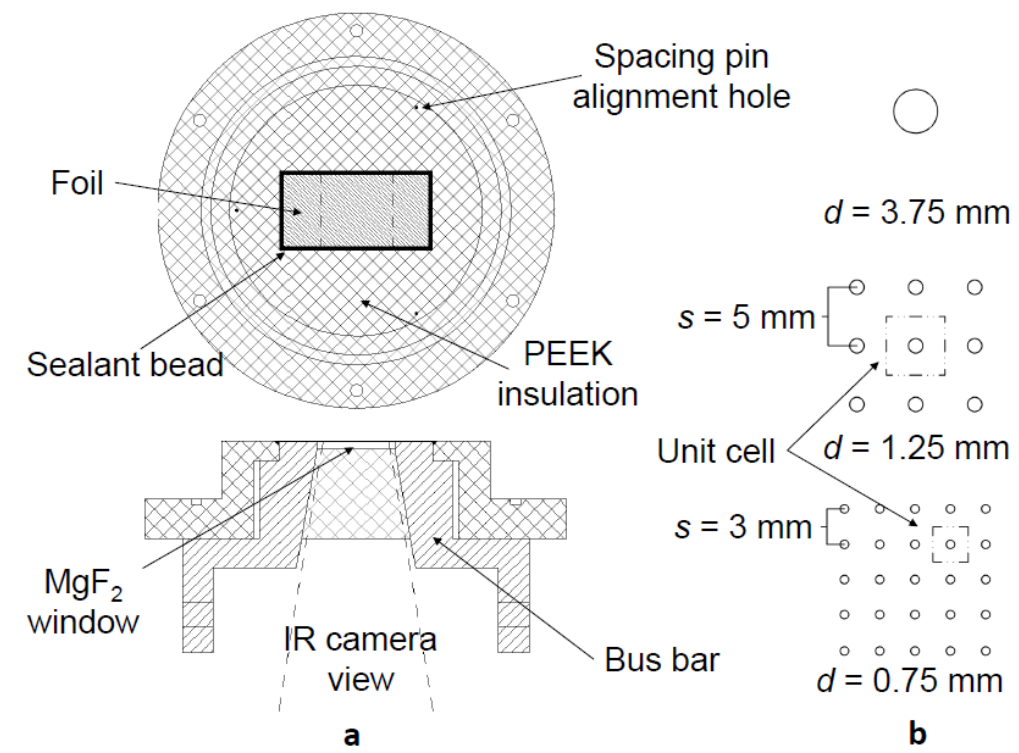

Figure 3. Illustration of (a) the thin-foil heat source assembly and (b) orifice geometries. 


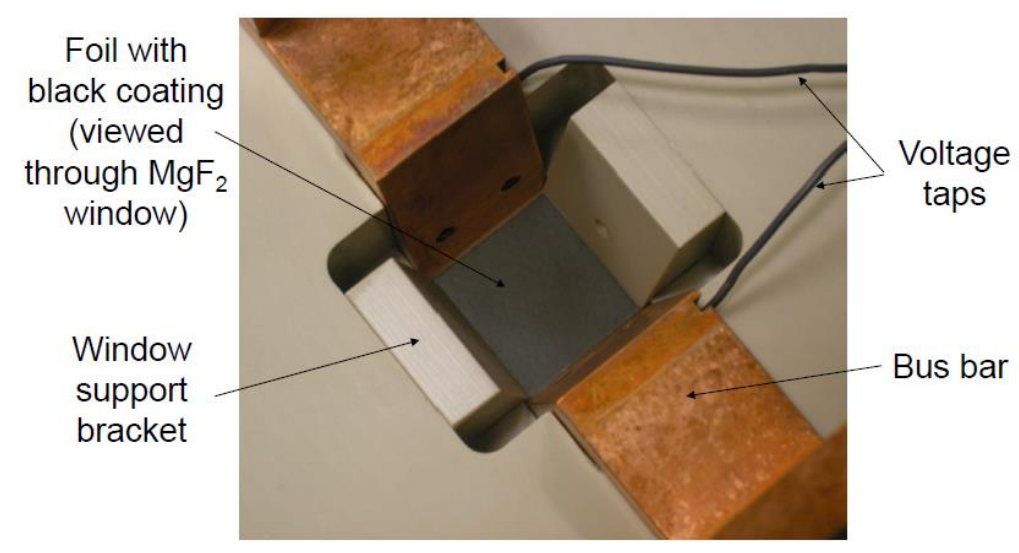

Figure 4. Photograph of the bottom of the heat source assembly. The black emissive coating is viewed through the $\mathrm{MgF}_{2}$ window, which is transparent in the IR and visible spectra. 


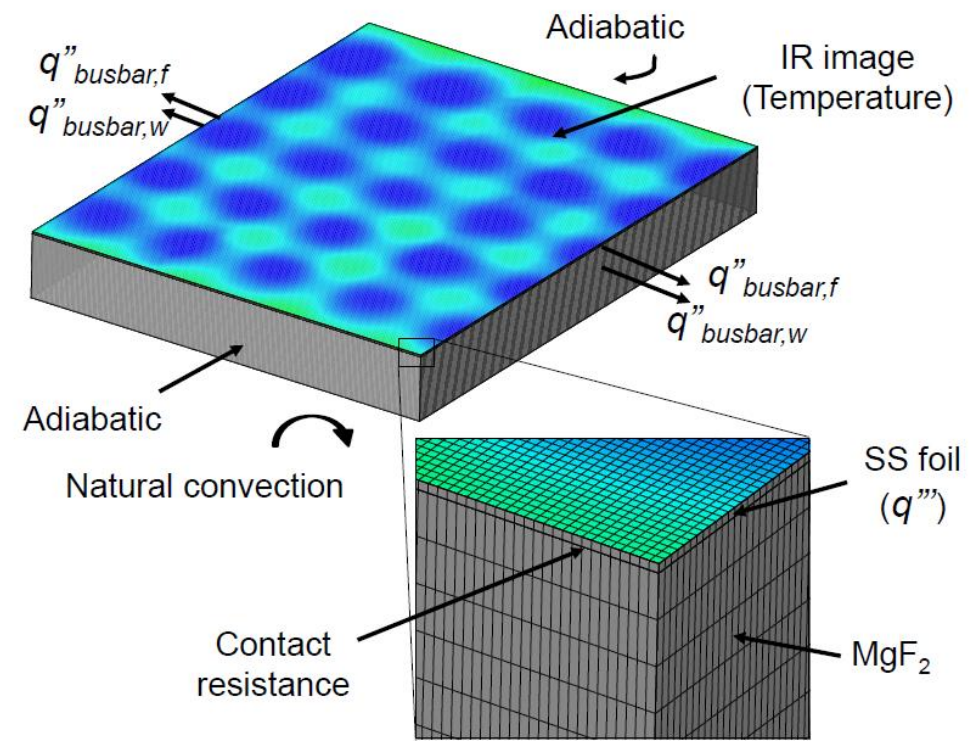

Figure 5. Schematic illustration of the 3D conduction domain and boundary conditions used for local heat flux data reduction. 

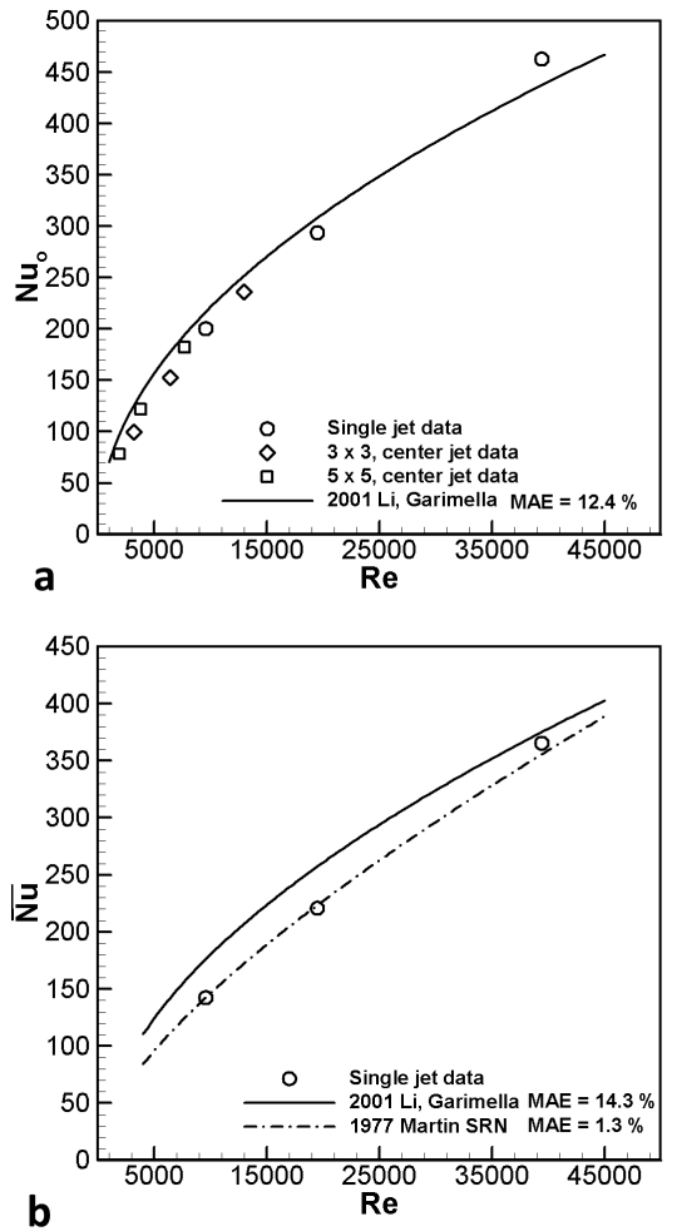

Figure 6. (a) stagnation point Nusselt numbers compared with equation 8 in [41], and (b) area-averaged Nusselt numbers compared with equation 18 in [41] and equation 4.10 in [42]. 

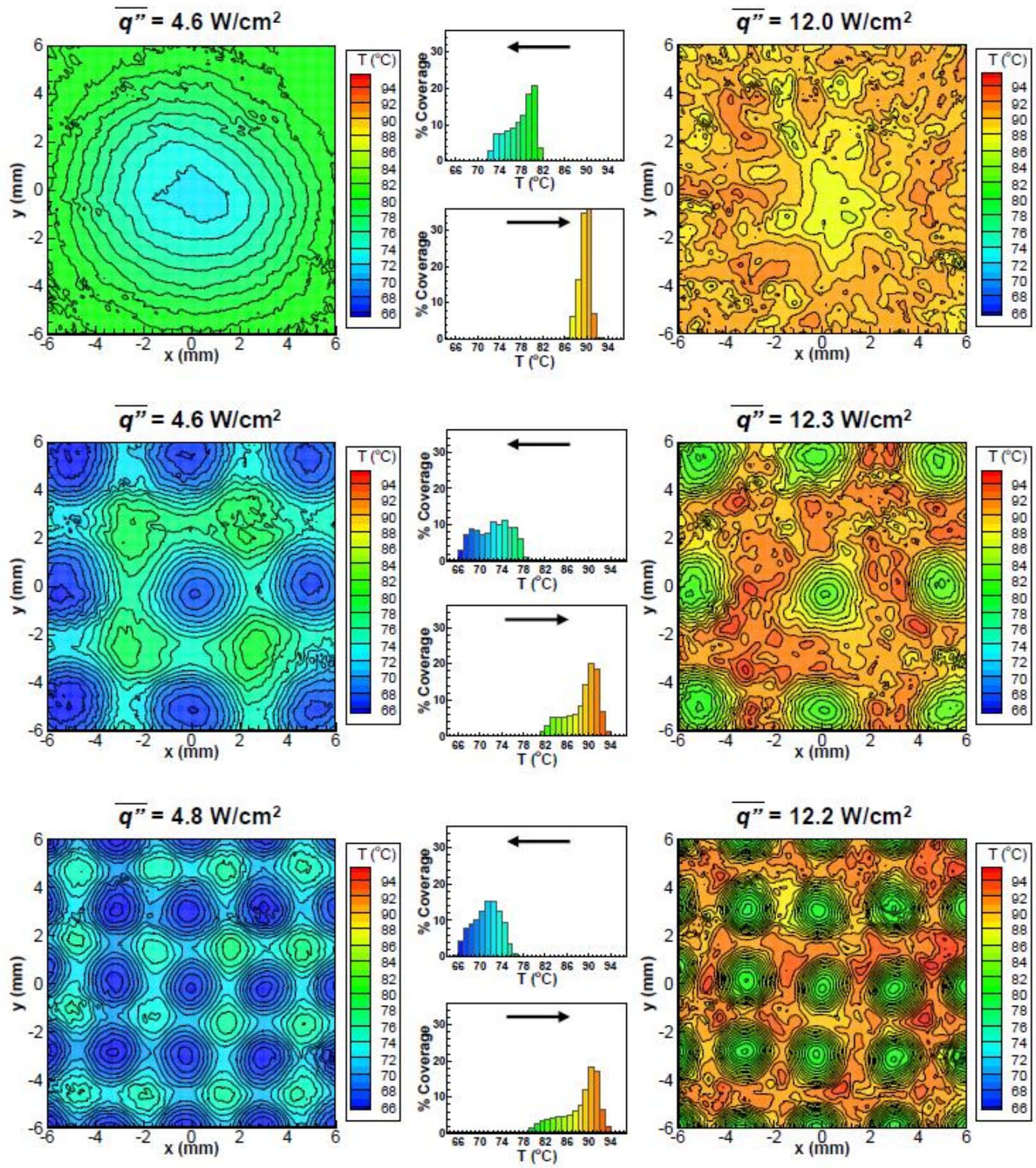

a

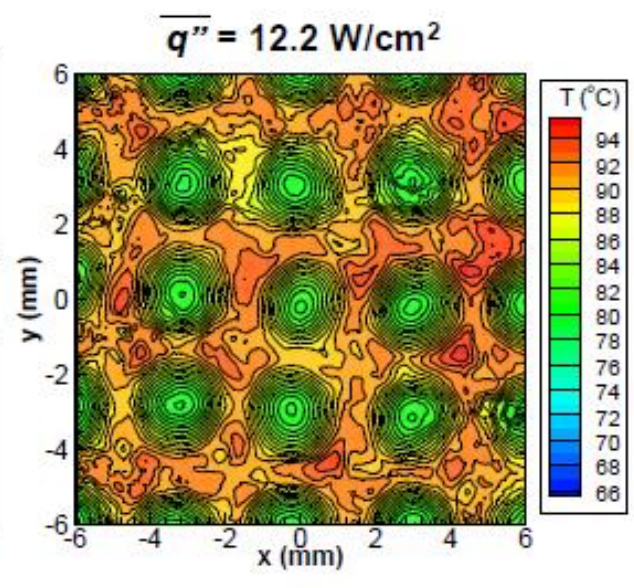

b

Figure 7. (a) Single-phase and (b) two-phase temperature maps with histograms (center) for the (from top to bottom) single jet, $3 \times 3$ array, and $5 \times 5$ array. 

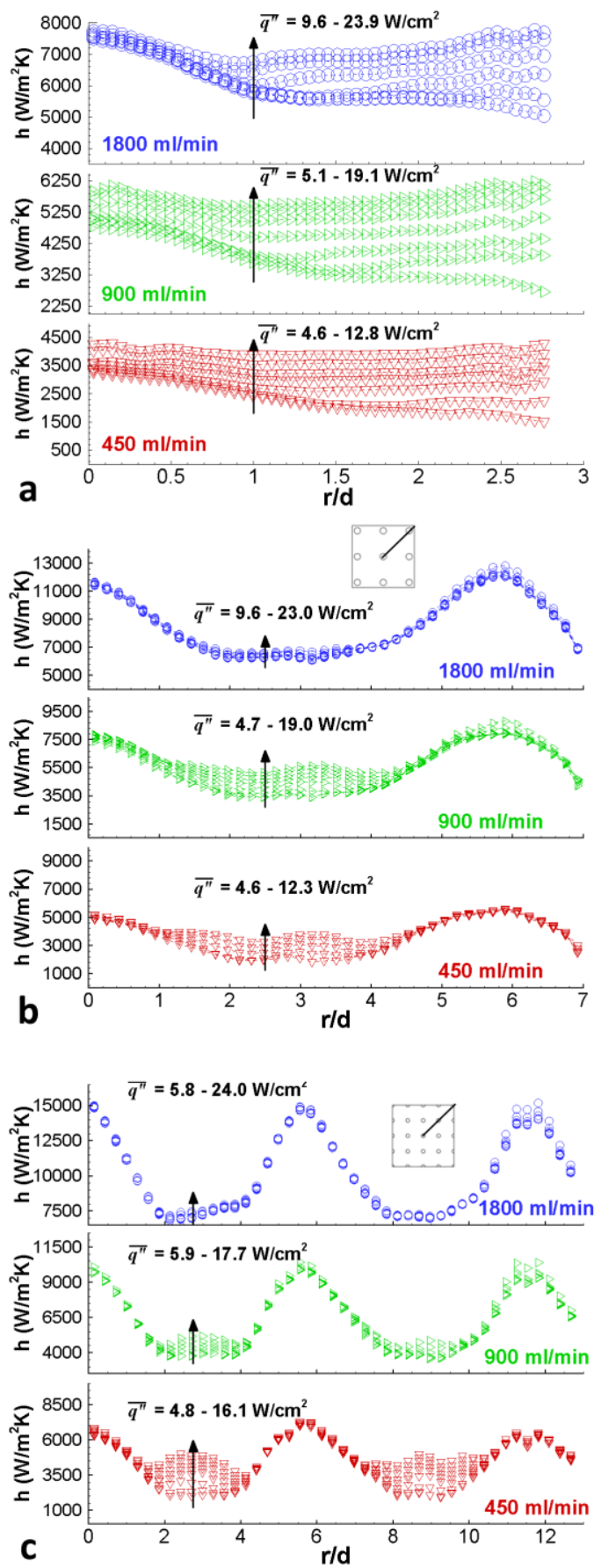

Figure 8. Heat transfer coefficient profiles for the (a) single jet $(d=3.75 \mathrm{~mm}),(\mathrm{b}) 3 \times 3$ array $(d=1.25$ $\mathrm{mm})$, and (c) $5 \times 5$ array $(d=0.75 \mathrm{~mm})$ at flow rates of 450,900 , and $1800 \mathrm{ml} / \mathrm{min}$ for a range of heat fluxes. 

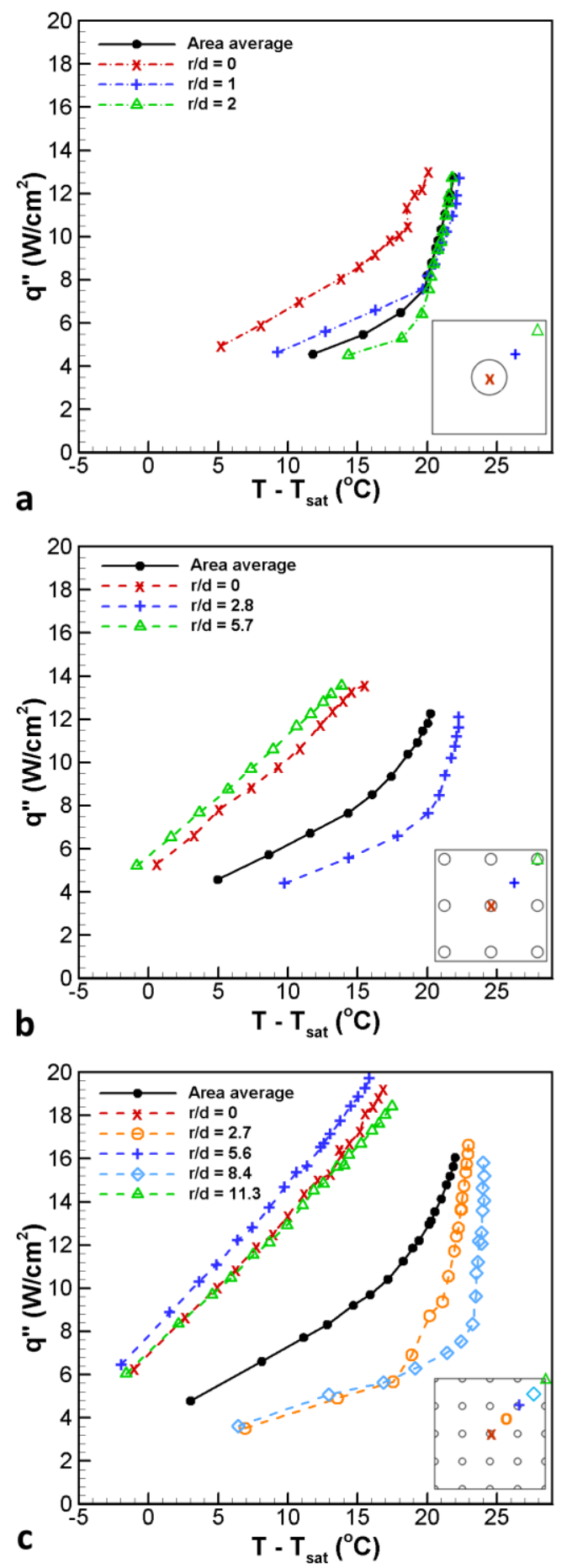

Figure 9. Local boiling curves for (a) the single jet $(d=3.75 \mathrm{~mm})$, (b) the $3 \times 3$ array $(d=1.25 \mathrm{~mm})$, and (c) the $5 \times 5$ array $(d=0.75 \mathrm{~mm})$ at a flow rate of $450 \mathrm{ml} / \mathrm{min}$. 


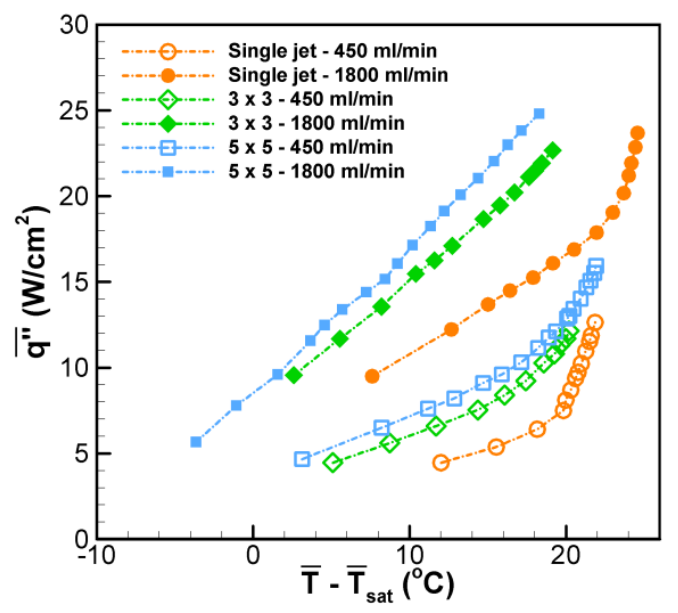

Figure 10. Area-averaged boiling curves for the single jet $(d=3.75 \mathrm{~mm}), 3 \times 3$ array $(d=1.25 \mathrm{~mm})$, and $5 \times 5$ array $(d=0.75 \mathrm{~mm})$ for flow rates of 450 and $1800 \mathrm{ml} / \mathrm{min}$. 


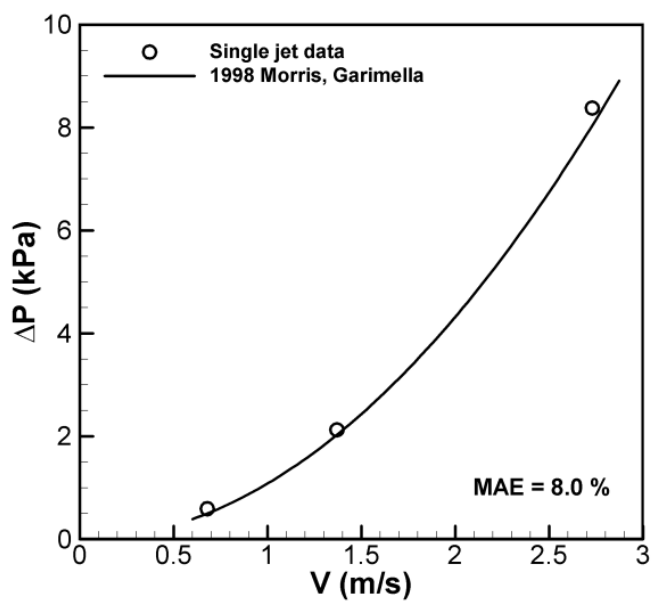

Figure 11. Single-phase pressure drop for the single jet compared to equation 3 in [26]. 


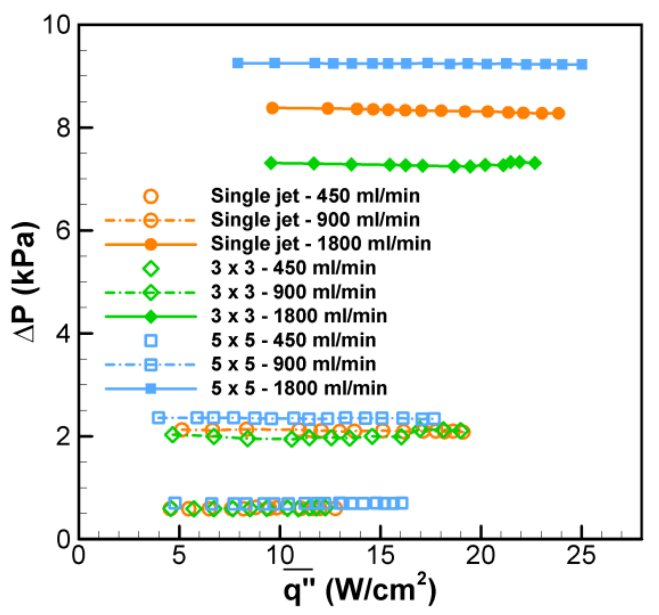

Figure 12. Pressure drop for the single jet $(d=3.75 \mathrm{~mm}), 3 \times 3$ array $(d=1.25 \mathrm{~mm})$, and $5 \times 5$ array $(d=$ $0.75 \mathrm{~mm}$ ) at flow rates of 450,900 , and $1800 \mathrm{ml} / \mathrm{min}$ as a function of heat flux. 